\title{
Benefit of Cochlear Implantation in Children with Multiple-handicaps: Parent's Perspective
}

\author{
Heloisa Romeiro Nasralla ${ }^{1}$ Adilson Marcos Montefusco ${ }^{2}$ Ana Cristina H. Hoshino ${ }^{1}$ \\ Paola Angelica Samuel ${ }^{2}$ Ana Tereza de Matos Magalhães ${ }^{1}$ Maria Valéria Schmidt Goffi-Gomez ${ }^{2}$ \\ Robinson Koji Tsuji ${ }^{2}$ Ricardo Ferreira Bento ${ }^{2}$
}

${ }^{1}$ Cochlear Implant Group, Hospital das Clinicas HCFMUSP, Faculdade

de Medicina, Universidade de São Paulo, São Paulo, SP, BR

Address for correspondence Heloisa Romeiro Nasralla, Cochlear

2 Department of Otorhinolaryngology, Faculdade de Medicina FMUSP, Implant Group, Rua Capote Valente, 432, $1^{\circ}$ andar, Cj. 14 - Pinheiros, Universidade de São Paulo, São Paulo, SP, BR

Int Arch Otorhinolaryngol 2018;22:415-427.

\begin{abstract}
Introduction The cochlear implants centers in the world are studying the cochlear implantation in children with multiple handicaps.

Objective To develop a questionnaire to analyze the subjective benefits of the cochlear implantation in multiple handicapped children according to their parent's perspective.

Methods A questionnaire was applied to 14 families of multiple handicapped children, aging from 2-12 years old and having from 11 months to 11 years of implant use.

Results The social-emotional abilities were improved because of many factors, such as: auditory exposure, which happened in $84 \%$ of the children; recognition of their own names, which increased in 56\%; and development of eye contact, in $28 \%$ of the subjects. Other benefits appeared to be: music appreciation and more attention and adherence to other therapies and school activities. Besides, some children became interested in objects, playing with other children, and more adapted to daily routines. Thirty-five percent of the children acquired oral language, mainly the bilaterally implanted, while $14 \%$ of them were engaged in sign language. Although all of the children showed a significant improvement in communication, the emotional issues of some families and the severity of the handicaps negatively impacted the outcomes. In spite of the families' acknowledgement of some benefits, the diagnosis of autism

\section{Keywords}

- deafness

- multiple handicaps

- cochlear implants

- quality of life spectrum disorder caused frustration, requiring a readjustment of the expectations. Conclusion The questionnaire turned out to be an adequate tool to reveal the socialemotional benefits of cochlear implantation. Although oral language was not the major outcome in these cases, the cochlear implant benefits involved the whole family. All of the families recommended the implant to other children in a similar situation.
\end{abstract}

\section{Introduction}

Cochlear implants (CIs) in deaf children with multiple disabilities have been the object of study in major implant centers $^{1-11}$ because they represent $30-40 \%$ of $\mathrm{CI}$ cases, $3,7,8$ and because their heterogeneity and complexity can lead to variable outcomes. Although CIs have a limited impact on speech perception and language skills, they are reported to have benefits in daily life. Originally, deaf children with multiple disabilities were not candidates for CIs; in recent received

July 3, 2017

accepted

January 21, 2018

published online

April 26, 2018
DOI https://doi.org/

10.1055/s-0038-1642607. ISSN 1809-9777.
Copyright $(2018$ by Thieme Revinter

Publicações Ltda, Rio de Janeiro, Brazil
License terms

(요 (1) $\Theta \circledast$ 
decades, they have been included, ${ }^{12,13}$ increasing the number of children in this subgroup who now receive CIs. As a result, there is an urgent need to develop adequate instruments to assess the impact of CIs on this population, to support future indications and expectations, and to follow up. $^{7,8,14}$

Children with other associated handicaps are affected by cytomegalovirus (CMV), Usher syndrome, motor and/or cognitive delays, meningitis after-effects, or various infections. Some children may also have socio-emotional and interaction problems or autism spectrum disorder (ASD). Jure et $\mathrm{al}^{15}$ reported that $4 \%$ of deaf children have ASD, in comparison with $1 \%$ of the hearing population. Donaldson et $\mathrm{al}^{9}$ evaluated seven deaf children with autism who received CIs and concluded that oral communication is not an objective to be achieved. Although only one child with mild autism acquired speech after CIs, all the parents reported benefits, with five families saying that they would recommend implants to others in the same situation. Donaldson et $\mathrm{al}^{9}{ }^{9}$ Wiley et $\mathrm{al}^{7}{ }^{7}$ and Berrettini et $\mathrm{al}^{8}$ have focused on evaluating the qualitative benefits of CIs. The latter two groups have worked with multiple deficiencies, using questionnaires designed for this purpose. They too have reported improvements in these patients' quality of life, regardless of speech acquisition.

In a recent study on the qualitative post-implant benefits reported by the parents of these patients, Mulla et $\mathrm{al}^{16}$ made an interesting observation that his team delayed the decision to carry out cochlear implantation on patients who had additional disabilities. Here, in our cochlear implant group, this does not happen, which is not to say that CIs are always indicated in cases that involve a poor auditory processing potential, serious neurological impairments or others impediment issues.

According to Berrettini et $\mathrm{al}^{8}{ }^{8}$ a third of the children who receive CIs at an early age may manifest other problems, thus leading to frustration due to unmet expectations. We have observed such indications in the present study, especially in relation to autism, and have followed these cases particularly closely. However, there is no way to prevent children from being diagnosed with such problems long after their implantations. When this happens, the use of CIs can be greatly impaired, creating disharmony between parents and children due to poorly achieved expectations, difficulties in accepting other treatments, and delayed benefits. Whenever progress with $\mathrm{CI}$ is not as expected, the child should be immediately evaluated. ${ }^{13,17,18}$ The need for an early diagnosis justifies the involvement of a team of psychologists in CI teams to identify children with learning disorders, specific cognitive deficits that have implications for rehabilitation, or nonverbal cognitive abilities that can predict the child's language evolution. It is also important to note the child's learning style and the emotional and behavioral commitments of both patients and parents, as these can impact both progress and social adjustment and problem-solving skills.

Our objective in this work has been to develop a questionnaire in Portuguese to analyze the subjective and qua- litative benefits of CIs in children with multiple disabilities from the parents' perspective.

\section{Methods}

This study was approved by the ethics committee under protocol number CAAE: 57300316.0.0000.0068. All the participants signed an informed consent agreement.

Using the results presented by Donaldson et $a l,{ }^{9}$ Wiley et $\mathrm{al}^{7}$ and Berrettini et $\mathrm{al}^{8}{ }^{8}$ we developed the Nasralla questionnaire (-Supplementary Material 1 and 2), which is specifically addressed to the parents of implanted deaf children with associated disabilities in our cochlear implant group, to ascertain and define the benefits of $\mathrm{CI}$ for these children. The questionnaire has been adjusted to suit our realities, based on our experience. We interviewed 14 families of children with multiple disabilities who attended routine $\mathrm{CI}$ programs during the study collection period. We collected their medical records, which contained information about associated disabilities, other treatments, implant use time, and other constraints.

In the hearing and language categories, data were collected during the evaluation of the $\mathrm{CI}$ fitting and classified using the categories of auditory perception proposed by Geers, ${ }^{19}$ as well as Garrido and Flores' category $7^{20}$ and language categories ${ }^{21}$ (-Table 1).

The following components were included in our questionnaire: ${ }^{1}$ patient identification, ${ }^{2}$ associated deficiency, ${ }^{3}$ time of surgery and activation, ${ }^{4}$ whether the $\mathrm{CI}$ was unilateral or bilateral, sequential, or simultaneous, ${ }^{5}$ daily device-use time, and ${ }^{6}$ support between partners in the couple, from the extended family, or from professionals who attended them. The following open-ended questions were also included: ${ }^{1}$ what advantages the parents saw in $\mathrm{CI}^{2}{ }^{2}$ the child's pre-CI and post-CI communication skills, ${ }^{3}$ whether the patients had communicative intent, and ${ }^{4}$ the status prior and post-implantation of either nonverbal and verbal communication or sign language. These were later classified by legend for definition of communication type as shown in - Table 2. Their schooling, if they did other therapies and found difficulty in accessing them, as well as general comments. In the closed questions, we examined the child's social-emotional abilities by investigating his or her reactions, interests, behaviors, temperament, family and social interactions, independence during activities of daily life (ADL), adaptive potential, self-control, openness to experiences, and learning styles. In closing, we asked about the parents' expectations regarding the $\mathrm{CI}$ intervention and whether these were fulfilled. We also asked parents if they would recommend the $\mathrm{CI}$ to another child under the same conditions. The questionnaire was published in both Portuguese and English (-Supplementary Material 1 and 2). The data were analyzed qualitatively.

\section{Results}

The mean age of the patients at the time of the study was 6 years, 5 months old (minimum: 2 years, 5 months; 
Table 1 Categories of auditory perception and language

\begin{tabular}{|c|c|}
\hline \multicolumn{2}{|l|}{ Categories of auditory perception (Geers, 1994) } \\
\hline CATEGORY 0 - Does not detect speech & $\begin{array}{l}\text { CATEGORY } 5 \text { - Identification of words through recognition of } \\
\text { the consonant }\end{array}$ \\
\hline $\begin{array}{l}\text { CATEGORY } 1 \text { - Speech detection without differentiating the } \\
\text { stimulus }\end{array}$ & \multirow{2}{*}{$\begin{array}{l}\text { CATEGORY } 6 \text { - Recognition of words in open set. This child is } \\
\text { able to hear words out of context and extract enough } \\
\text { phonemic information and recognize the word exclusively } \\
\text { through hearing. }\end{array}$} \\
\hline $\begin{array}{l}\text { CATEGORY } 2 \text { - Pattern of perception (differentiates words by } \\
\text { supra-segmental traits). }\end{array}$ & \\
\hline $\begin{array}{l}\text { CATEGORY } 3 \text { - Starting the identification of words. This child } \\
\text { differentiates between closed-set words based on phonetic } \\
\text { information. }\end{array}$ & \multirow{2}{*}{$\begin{array}{l}\text { CATEGORY } 7 \text { - Open-ended word recognition. This child is } \\
\text { able to hear words out of context and extract enough } \\
\text { phonemic information and recognize the word exclusively } \\
\text { through hearing. Especially in everyday situations (in the } \\
\text { classroom, on the phone, when listening to an alphabet song, } \\
\text { when watching a TV program), the child always understands, } \\
\text { only by hearing. (Garrido and Flores, 2014) }\end{array}$} \\
\hline $\begin{array}{l}\text { CATEGORY } 4 \text { - Identification of words by means of vowel } \\
\text { recognition. This child differentiates between closed-set } \\
\text { words that differ primarily in the sound of the vowel. }\end{array}$ & \\
\hline \multicolumn{2}{|l|}{ Categories of language (Bevilacqua et al, 1996) } \\
\hline $\begin{array}{l}\text { CATEGORY } 1-\text { This child does not speak and may present } \\
\text { undifferentiated vocalizations. }\end{array}$ & $\begin{array}{l}\text { CATEGORY } 4-\text { This child builds sentences of four or five } \\
\text { words, and begins to use connective elements (pronouns, } \\
\text { articles, prepositions). }\end{array}$ \\
\hline CATEGORY 2 - This child speaks only isolated words. & \multirow{2}{*}{$\begin{array}{l}\text { CATEGORY } 5 \text { - This child constructs sentences of more than } \\
\text { five words, using connective elements, conjugating verbs, } \\
\text { using plurals, etc. She is fluent in oral language. }\end{array}$} \\
\hline $\begin{array}{l}\text { CATEGORY } 3-\text { This child builds sentences of two or three } \\
\text { words. }\end{array}$ & \\
\hline
\end{tabular}

maximum: 13 years, 6 months) and the average use of the implant was 3 years, 6 months old (minimum: 9 months; maximum: 11 years, 1 month).

In the classification of the category of hearing and language, we observed different responses among subjects. Nine of the 14 patients were unable to develop speech and were only able to detect the sounds without discrimination. However, those patients who managed to evolve in the hearing categories also observed an evolution in their spoken language. (-Tables 3 and 4 ).

Of the 14 patients, half had been implanted unilaterally by the Brazilian public health system, which, at that time,

Table 2 Communication pre- and post-cochlear implant (Cl)

\begin{tabular}{|c|c|c|c|c|}
\hline \multicolumn{5}{|l|}{ Communication Skills } \\
\hline \multicolumn{5}{|c|}{ Legend for definition of communication type: } \\
\hline \multicolumn{5}{|c|}{ - No intention of communication (NIC) } \\
\hline \multicolumn{5}{|c|}{ - Behavioral reaction (BR): cry, scream, facial expression, vocalizations, and gestures } \\
\hline \multicolumn{5}{|c|}{ - Behavioral reactions/signals (BRS): cry, scream, facial expression, vocalizations, and gestures + signals } \\
\hline \multicolumn{5}{|c|}{ - Behavioral Reactions + a few clear words (BRW) } \\
\hline \multicolumn{5}{|c|}{ - Uses alternative communication (AC), such as drawings } \\
\hline \multicolumn{5}{|c|}{ - Oral/Signal (OS): combination of Brazilian Sign Language (LIBRAS) and clearly spoken words } \\
\hline \multicolumn{5}{|c|}{ - Oral (O): only words, without gestures or signals. } \\
\hline & PRE-Cl & & POST-Cl & \\
\hline Communication Skills & $\mathrm{N}$ & $\%$ & $\mathrm{~N}$ & $\%$ \\
\hline NIC & 3 & $21.4 \%$ & 0 & $0 \%$ \\
\hline BR & 11 & $78.6 \%$ & $5\left({ }^{*} 2\right.$ with $\left.B R+A C\right)$ & $35.7 \%$ \\
\hline BRS & 0 & $0 \%$ & 2 & $14.3 \%$ \\
\hline BRW & 0 & $0 \%$ & 1 & $7.1 \%$ \\
\hline OS & 0 & $0 \%$ & 2 & $14.3 \%$ \\
\hline LIBRAS & 0 & $0 \%$ & 2 & $14.3 \%$ \\
\hline $\mathrm{O}$ & 0 & $0 \%$ & 2 & $14.3 \%$ \\
\hline
\end{tabular}


Table 3 Sample demographics

\begin{tabular}{|c|c|c|c|c|}
\hline Patients & Sex & $\begin{array}{l}\text { Age at cochlear } \\
\text { implantation }\end{array}$ & $\begin{array}{l}\mathrm{Cl} \text { Brand } \\
\text { right/left side }\end{array}$ & Speech processor \\
\hline 1. MRMC & M & 1 yr. 8 mos. & Freedom Implant Contour (L) & Freedom \\
\hline 2. RRM & M & 3 yrs. 8 mos. & Freedom Implant Contour (L) & CP810 \\
\hline 3. RSM & M & 3 yrs. 8 mos. & Freedom Implant Contour (R/L) & CP 810 \\
\hline 4. ALS & $\mathrm{F}$ & 3 yrs. & Nucleus 24M/K (R) & CP810 \\
\hline 5. IMM & $\mathrm{F}$ & 1 yr. 3 mos. & Freedom Implant Contour (R/L) & CP810 \\
\hline 6. MPM & $\mathrm{F}$ & 1 yr. 7 mos. & Freedom Implant Straight (R/L) & Freedom \\
\hline 7. GML & $\mathrm{F}$ & 2 yrs. 5 mos. & Freedom Implant Contour (R/L) & CP810 \\
\hline 8. KLSB & M & 3 yrs. 3 mos. & Freedom Implant Contour (R) & Freedom \\
\hline 9. CAS & $\mathrm{F}$ & 4 yrs. & Freedom Implant Contour (R/L) & CP810 \\
\hline 10. LCR & M & 1 yr. 4 mos. & Freedom Implant Contour (R/L) & CP810 \\
\hline 11. FSA & $\mathrm{F}$ & 1 yr. 10 mos. & Freedom Implant Contour (L) & CP810 \\
\hline 12. $A B C A$ & $\mathrm{~F}$ & 5 yrs. 1 mo. & $\mathrm{Cl} 512(\mathrm{R})$ & CP810 \\
\hline 13. ESV & $\mathrm{M}$ & 3 yrs. 7 mos. & Freedom Implant Contour (R/L) & CP810 \\
\hline 14. LGFA & M & 3 yrs. 11 mos. & Digisonic SP 20 eletrodes (L) & DigiSP/K \\
\hline Mean & & 2 yrs. 8 mos. & & \\
\hline
\end{tabular}

Abbreviation: $\mathrm{Cl}$, cochlear implant.

offered only one implant to each patient. Those with bilateral $\mathrm{CI}$ had been treated by the private health system.

As for the etiology of deafness, more than half of the patients had prematurity and CMV, as well as delayed neuro-

Table 4 Auditory categories and language of sample

\begin{tabular}{|l|l|l|l|}
\hline Patients & Period of Cl use & $\begin{array}{l}\text { Auditory } \\
\text { categories } \\
\text { (Geers, } \\
\text { 1994; } \\
\text { Garrido } \\
\text { and } \\
\text { Flores, } \\
\text { 2014) }\end{array}$ & $\begin{array}{l}\text { Categories } \\
\text { of Language } \\
\text { (Bevilacqua } \\
\text { et al., 1996) }\end{array}$ \\
\hline 1. MRMC & 4 yrs. 11 mos. & 1 & 1 \\
\hline 2. RRM & 9 mos. & 1 & 1 \\
\hline 3. RSM & 1 yr. 5 mos. & 1 & 1 \\
\hline 4. ALS & 9 yrs. 8 mos. & 5 & 4 \\
\hline 5. IMM & 1 yr. 2 mos. & 1 & 1 \\
\hline 6. MPM & 3 yrs. 2 mos. & 3 & 3 \\
\hline 7. GML & 11 yrs. 1 mo. & 7 & 5 \\
\hline 8. KLSB & 2 yrs. 3 mos. & 1 & 1 \\
\hline 9. CAS & 1 year & 2 & 2 \\
\hline 10. LCR & 3 yrs. & 4 & 3 \\
\hline 11. FSA & 4 yrs. 4 mos. & 1 & 1 \\
\hline 12. ABCA & 3 yrs. 7 mos. & 1 & 1 \\
\hline 13. ESV & 1 yr. 2 mos. & 1 & 1 \\
\hline 14. LGFA & 2 yrs. 4 mos. & 1 & 1 \\
\hline Mean & 3 yrs. 6 mos. & & \\
\hline
\end{tabular}

Abbreviations: mo(s), month(s); yr(s), year(s). psychomotor development (DNPD) and ASD, which are more frequent in cases of associated handicap ( - Table 5 ).

All but two of the children included in this study used their implants more than $75 \%$ of the time. Of these two, one was identified with autism, with motor and severe cognitive delays; this child was bothered by the sound, a problem that is now being addressed in therapy. The other child was identified with visual and emotional problems in addition to relational difficulties with the mother.

All the interviewed parents had received help and support from a partner, their extended family, and from professionals who attended them. In addition to regular speech processor fitting sessions at the CI group, approximately once every 3 months or according to individual need, the patients underwent other therapies, including speech therapy, equine therapy, physiotherapy, occupational therapy, and emotional and psychopedagogical therapy. When asked whether it was difficult taking their children to these therapies, three mothers reported problems due to their children's behavior. When asked about communication skills, many parents claimed that their children became part of the world after their $\mathrm{CI}$, suggesting significant improvement. The results are summarized in - Table 2.

The demographic data and communication details of children with bilateral and unilateral $\mathrm{CI}$ are summarized in -Tables 6 and 7.

Among those with bilateral implantation, we observed better speech development and less impact from additional impairments. In particular, four children developed some speech after implantation, with two children with 3 years and 2 months and 11 years and 1 month of stimulation exhibiting no speech problems. The first of these patients, who was hyperkinetic and repetitive in speech and behavior, 
Table 5 Sample distribution of cochlear implant side, etiology, and associated handicaps

\begin{tabular}{|l|l|l|}
\hline Cochlear implant side & $\mathrm{N}$ & $\%$ \\
\hline Unilateral & 7 & $50 \%$ \\
\hline Simultaneous bilateral & 5 & $35.7 \%$ \\
\hline Sequential bilateral & 2 & $14.3 \%$ \\
\hline Etiology & $\mathrm{N}$ & $\%$ \\
\hline Prematurity & 5 & $35.7 \%$ \\
\hline Unknown & 4 & $28.6 \%$ \\
\hline CMV & 3 & $21.4 \%$ \\
\hline Rubella & 1 & $7.1 \%$ \\
\hline Sepsis and perinatal events & 1 & $7.1 \%$ \\
\hline Associated handicap & $\mathrm{N}$ & $\%$ \\
\hline $\begin{array}{l}\text { Delayed neuro-psychomotor } \\
\text { development (DNPD) }\end{array}$ & 5 & $35.7 \%$ \\
\hline $\begin{array}{l}\text { Autism spectrum disorder } \\
\text { (ASD) }\end{array}$ & 4 & $28.6 \%$ \\
\hline $\begin{array}{l}\text { Global developmental delay } \\
\text { (GDD) }\end{array}$ & 2 & $14.3 \%$ \\
\hline $\begin{array}{l}\text { Attention deficit and } \\
\text { hyperactivity disorder } \\
\text { (ADHD)/emotional }\end{array}$ & 1 & $7.1 \%$ \\
\hline $\begin{array}{l}\text { Cerebral palsy (CP) } \\
\text { Visual/cognitive and emotional } \\
\text { problems }\end{array}$ & 1 & $7.1 \%$ \\
\hline
\end{tabular}

Abbreviations: BR, Behavioral reaction; BRS, Behavioral reactions/ signals; O, Oral.

acquired speech after learning Brazilian Sign Language (LIBRAS, in the Portuguese acronym). In the case of the latter patient, the second implantation was performed 4 years after the first implant, and the patient's mother attributed this child's development of oral language to the second implant. These two patients were precisely those who had the most severe impairments and exhibited the most advanced motor recovery after $\mathrm{CI}$, which contributed to their access to sound, as previously reported by Azema and Virole. ${ }^{22}$ of the two patients with emotional problems, one spoke insufficiently, articulating only a few words and using gestures to communicate. This child, who preferred to express himself through emotions, regressed significantly in his psychic development. The other patient expressed a certain refusal to speak. In this case, underdeveloped oral language and barriers caused by the denial of deafness and maternal overprotection held back oral development, which did not achieve its full potential. Two other children vocalized after 1 year and 2 months of stimulation. One of them, who used gestures at 5 years of age and who had been diagnosed with ASD, spoke in therapy but did not talk at home. This patient became more attentive to the environment after $\mathrm{CI}$, but still failed to make eye contact, recognize names, or react to sounds. The family does not stimulate this child and has reacted badly to the diagnosis, in part because the parents feel guilty that his attention deficit hyperactivity disorder (ADHD) may be due to the fact that they are cousins. Despite only vocalizing, one child with a history of extreme prematurity, mild cognitive impairments, and a cerebellar lesion has shown greater interest in everything and is currently learning LIBRAS at the mother's initiative. The last child in the study had a marked global developmental delay (GDD) but began to signal and vocalize-imitating speech-after only 1 year and 2 months of stimulation and learning LIBRAS at school.

Among the patients with unilateral implants were seven children with more severe additional disabilities. Six of them had received stimulation for a period ranging from 9 months to 4 years and 11 months, and one had spent 9 years and 8 months receiving auditory stimulation through a $\mathrm{CI}$. The latter, a very isolated girl diagnosed with ASD (mild) with mild

Table 6 Patients with bilateral cochlear implant $(\mathrm{Cl})$

\begin{tabular}{|c|c|c|c|c|c|}
\hline Patients & Impairment & Age & Cl Time & Pre-Cl & Post-Cl \\
\hline CAS & $\begin{array}{l}\text { Attention deficit hyperactivity } \\
\text { disorder (ADHD) / emotional }\end{array}$ & 5 yrs. & $1 \mathrm{yr}$. & Gestures & $\begin{array}{l}\text { Speaks words / a phrase / little } \\
\text { comprehension }(\mathrm{O})\end{array}$ \\
\hline LCR & $\begin{array}{l}\text { Delayed neuro-psychomotor } \\
\text { development (DNPD) / cleft lip } \\
\text { palate / emotional }\end{array}$ & 4 yrs. 4 mos. & 3 yr. & Gestures & $\begin{array}{l}\text { Speaks little / gestures / }+ \\
\text { interested / express emotions } \\
\text { (BRW) }\end{array}$ \\
\hline MPM & DNPD / ADHD & 4 yrs. 9 mos. & 3 yrs. 2 mos. & $\begin{array}{l}\text { Screams / } \\
\text { echolalia }\end{array}$ & LIBRAS later speaking (OS) \\
\hline GML & $\begin{array}{l}\text { DNPD / partial vision / } \\
\text { equilibrium }\end{array}$ & $\begin{array}{l}13 \text { yrs. } 6 \\
\text { mos. }\end{array}$ & $\begin{array}{l}11 \text { yrs. } 1 \\
\text { mo. / } 7 \text { yrs. }\end{array}$ & $\begin{array}{l}\text { Without } \\
\text { communi- } \\
\text { cative } \\
\text { intention }\end{array}$ & Speaks after 2 nd implant (O) \\
\hline RSM & $\begin{array}{l}\text { Autism spectrum disorder } \\
\text { (ASD) / ADHD }\end{array}$ & 5 yrs. 3 mos. & 1 yr. 5 mos. & $\begin{array}{l}\text { Spoke until } \\
1 \text { yr } 6 \text { mos }\end{array}$ & Vocalizations and gestures (BR) \\
\hline IMM & $\begin{array}{l}\text { DNPD and mild cognitive / } \\
\text { cerebellar lesion }\end{array}$ & 2 yrs. 5 mos. & 1 yr. 2 mos. & Gestures & Vocalizes /+ active (BR) \\
\hline ESV & $\begin{array}{l}\text { Global developmental delay } \\
\text { (GDD) }\end{array}$ & 4 yrs. 9 mos. & 1 yr. 2 mos. & Gestures & $\begin{array}{l}\text { Signals / LIBRAS school / voca- } \\
\text { lizes imitating speech (BRS) }\end{array}$ \\
\hline
\end{tabular}

Abbreviations: BR, behavioral reaction; BRS, behavioral reactions/signals; Cl, cochlear implant; mo(s), month(s); O, oral; OS, oral/signal; yr(s), year(s). 
Table 7 Patients with unilateral cochlear implants $(\mathrm{Cl})$

\begin{tabular}{|l|l|l|l|l|l|}
\hline Patients & Impairment & Age & Cl Time & Pre-Cl & Post-CI \\
\hline MRMC & $\begin{array}{l}\text { Autistic spectrum disorder } \\
\text { (ASD) (mild), diagnosed } \\
\text { post-3 years of Cl / } \\
\text { Attention deficit } \\
\text { hyperactivity disorder } \\
\text { (ADHD) }\end{array}$ & 6 yrs. 7 mos. & 4 yrs. 11 mos. & Gestures & $\begin{array}{l}\text { Brazilian Sign Language } \\
\text { (LIBRAS) / shouts / loud } \\
\text { sound disturbs (LIBRAS) }\end{array}$ \\
\hline RRM & $\begin{array}{l}\text { ASD (serious motor and } \\
\text { cognitive delay) }\end{array}$ & 4 yrs. 7 mos. & 9 mos. & $\begin{array}{l}\text { Used } \\
\text { mother's } \\
\text { hand }\end{array}$ & $\begin{array}{l}\text { Babbles / looks / interacts } \\
+/ \text { remove process (BR) }\end{array}$ \\
\hline ALS & $\begin{array}{l}\text { ASD (mild) with mild motor } \\
\text { and cognitive delays }\end{array}$ & 12 yrs. 8 mos. & 9 yrs. 8 mos. & $\begin{array}{l}\text { Gestures / } \\
\text { screams }\end{array}$ & $\begin{array}{l}\text { Speaks / LIBRAS / does not } \\
\text { like noise (O) }\end{array}$ \\
\hline KLSB & $\begin{array}{l}\text { Visual/emotional/cognitive } \\
\text { problem }\end{array}$ & 5 yrs. 6 mos. & 2 yrs. 3 mos. & $\begin{array}{l}\text { Gestures / } \\
\text { touches / } \\
\text { unconnected }\end{array}$ & $\begin{array}{l}\text { LIBRAS / gestures / voca- } \\
\text { lizes / + aware (LIBRAS) }\end{array}$ \\
\hline FSA & $\begin{array}{l}\text { Delayed neuro-psychomotor } \\
\text { development (DNPD) and } \\
\text { cognitive / neurological } \\
\text { problems }\end{array}$ & 6 yrs. 2 mos. & 4 yrs. 4 mos. & $\begin{array}{l}\text { Without } \\
\text { communica- } \\
\text { tive intention }\end{array}$ & $\begin{array}{l}\text { Babbles / screams /+ } \\
\text { attentive and agile (BR) }\end{array}$ \\
\hline ABCA & $\begin{array}{l}\text { Cerebral palsy (CP) } \\
\text { LGFA }\end{array}$ & $\begin{array}{l}\text { Global developmental delay } \\
\text { (GDD) }\end{array}$ & 6 yrs. 3 mos. & 2 yrs. 4 mos. & $\begin{array}{l}\text { Pointed / } \\
\text { vocalized }\end{array}$ \\
\hline
\end{tabular}

Abbreviations: BR, behavioral reaction; BRS, behavioral reactions/signals; mo(s), month(s); O, oral; yr(s), year(s).

cognitive and motor delays, spoke after 5 years of stimulation and uses LIBRAS. Interestingly, the whole family of this patient has few social contacts, even among themselves. Her mother does not consider her a speaker, hopes that she will learn only sign language, and exhibits obvious denial of how far her daughter has progressed. Another patient with ASD, who uses LIBRAS and shouts to make himself noticed, was diagnosed 3 years after the implantation, which greatly affected his progress and disturbed his mother, who still does not accept his diagnosis and exhibits very frustrated expectations. The patient started to look at people 4 years after implantation and started LIBRAS at 4 years and 6 months after implantation; he has now had 4 years and 11 months of stimulation. The third autistic case was more serious, involving a younger child ( 4 years, 7 months old), with only 9 months of stimulation. This patient interacted and babbled more, exhibited improved eye contact, recognized his own name, and did not react to sound (improving). The patient, who has visual, cognitive, and emotional problems, for feeling rejected by the mother, came with his father. He reacts very badly to his mother. Both father and son use LIBRAS to communicate, a language that the mother does not know or accept because she wants her child to speak, probably to assuage her feelings of guilt over her son's deafness. Two other cases, one with cerebral palsy (CP) and the other with marked DNPD and cognitive impairments, had no communicative intention but began to communicate. The patient with $\mathrm{CP}$ showed speech comprehension and vocalization and made use of alternative forms of communication. The other patient (implanted for
4 years and 4 months) babbled, was more attentive and agile, and used screams. A patient with GDD with 2 years and 4 months of stimulation made some signs, screamed, and imitated lip movements.

Of the four autistic cases (both unilateral and bilateral), one spoke and used LIBRAS 5 years after implantation; one uses only LIBRAS at 4 years and 6 months post-CI, and the other two are interacting more at 9 months and 1 year and 5 months post-CI.

Despite the regrets, unmet expectations, and all the reported issues, which undoubtedly impacted the outcomes and benefits of implantation, the main and most exciting revelation of this study came through cases involving more serious conditions, when the mothers of several patients revealed that the implants made their children happier. Indeed, Steven et al, ${ }^{23}$ who worked specifically with implanted deaf patients with $\mathrm{CP}$, have reported that small audiological benefits can have great repercussions in the most severe cases, positively impacting the quality of life. The authors stress that other parents have more independent children with better motor skills.

In general, parents have reported that their children have become more communicative and sociable, adapting better to their environments.

In the present study, the best socio-emotional abilities appeared because of the children's reaction to sound, which benefited $84 \%$ of them, with $56 \%$ (from $21-77 \%$ ) demonstrating increased name recognition and 28\% (from 56-84\%) demonstrating increased eye contact. 
The reaction to sound and self-recognition provided emotional benefits, enabling the children to enjoy pleasures such as those provided by music (from 7-63\%), more adherence and attention to therapies (from 21-63\%), and school activities (100\%). We also observed improved interpersonal contact, as they answered $70 \%$ of the verbal questions, thus making them more communicative. Their increased ability to communicate desires and needs went from $49 \%$ pre-CI to $84 \%$ post-CI. They found it easier to comprehend speech than to express themselves.

Ocular contact, which was reported in $84 \%$ of the children after $\mathrm{CI}$, from an initial 56\%, brought many social benefits, such as becoming interested in objects (from 21-70\%), facilitating play with other children (from 56-91\%), showing initiative in play (from 49-84\%), adapting to the family routine (from 28-84\%), promoting oral language learning (35\%), and using sign language (14\%), and helping them to socially adapt to new situations (from $35-56 \%$ ) with positive reactions.

Their greater interest in school (100\%) compared with home $(70 \%)$ can be attributed to the emotional and behavioral issues already reported.

In addition to the skills that were less susceptible to change, including learning styles that were keeping them uncreative and incurious (from 21-38\%), we observed a few changes in temperament, involving traits of kindness, extroversion, or emotional instability (from 14-28\%).

Of the 14 parents who answered the questionnaire, eight said their children had done better than expected, and even the remaining six, who were frustrated with the results, saw some benefits. Indeed, all 14 parents said that they would recommend CIs. It was interesting to observe the parents who were frustrated: one was the mother who blamed herself for her child's deafness, and who had difficulty communicating with her child because she did not accept sign language and wanted her to speak instead. The others were all mothers of children with ASD: one was the mother of a child who was diagnosed 3 years after cochlear implantation, while two did not accept their children's diagnoses and expected more verbal fluency. Both the parents of children with emotional problems and autistic children are frustrated with the results.

The comments made by parents whose expectations were met or exceeded clearly indicate the importance of accepting the results and feeling satisfaction. Examples of such comments include: "The doctor said that he would listen, but not speak, but he ultimately spoke!"; "Maybe he would not listen, but then he heard with both ears ... and spoke!"; "Like those who were aware of difficulties and saw benefits ..."; and "No one gave hope. We knew he would not speak. But it helped a lot."

The sixth mother, who was frustrated with the outcome of the cochlear implantation, was the mother of the GDD patient whose outcome seems to be most disappointing because of her stimulus, effort and ambition, yet, she still sees benefits.

\section{Discussion}

The questionnaire was developed to capture the qualitative benefits of cochlear implantation, as perceived by parents and manifested in their children's daily lives. For this reason, we have created the first instrument in our country that is appropriate for our population. To create it, we adapted the ideas of Donaldson et al 2004, Wiley et al 2005, and Berretini et al 2008 (7-9), as described in their studies.

The parents' overwhelmingly positive responses to the invitation to be interviewed, and the joy with which they provided information revealed their satisfaction with the $\mathrm{CI}$. Simply interviewing the parents gave the interviewer much pleasure; it gave them an opportunity to talk about their joys and to share great emotions. The interviews themselves helped some parents become more aware of their child's progress and reflect on issues of family dynamics that were compromising it. This further indicated the need for a psychological follow-up to identify barriers to language acquisition. The early age at which these children have surgery does not allow for adequate expectations, particularly in cases of ASD. This has a negative impact on parents because they are not prepared to accept the diagnosis.

Many children with disabilities make progress following cochlear implantation, as previously reported. ${ }^{7,9}$ Some reports have found that they make less progress than children without disabilities, ${ }^{24}$ mainly in the area of speech development, which is consistent with our present findings. It was clear in our study that the $\mathrm{CI}$ led to a better quality of life for the whole family, despite the slow development of oral language, which was better in children who were implanted bilaterally. We noted that the parents' perception of qualitative benefits was independent of the children's development of oral or gestural language; this confirms the findings of Berrettini et al. ${ }^{8}$ All relational disjunctions were perceived by the children, who reacted to them with behavioral or more serious symptoms. However, even in these cases, there was a perception of relational benefits both at home (84\%), with better adaptation to routines, and at school, where the children found more satisfaction (100\%). In some cases, this finding revealed difficulties in the relationship between children and parents. In some cases, the parents' acceptance of their children's limitations ${ }^{13}$ compromised those children's outcomes and behaviors. Berrettini et al, $^{8}$ Robertson, ${ }^{18}$ Meinzen-Derr et al, $^{25}$ and Edwards ${ }^{13}$ reported that early diagnosis helps with setting expectations about and acceptance of diagnoses of autism and other serious impairments, favoring development and adherence to the treatment. This did not occur in six of our patients, causing their mothers to feel frustrated about their children's real potential.

Two of the children used their CI less than 75\% of the time. One patient, who had autism, was disturbed by the processor. Indeed, Robertson ${ }^{18}$ also referred to this issue, arguing that it was necessary to consider hearing intolerance and to measure sensory stimuli in such cases. The other patient was a very hectic child, who had relationship problems with his mother. Zaidman-Zait ${ }^{26}$ described a similar case of interpersonal difficulties with a mother, caused by insufficient communication, which caused stress within the family. Schoepflin et $\mathrm{al}^{27}$ associated such situations with a poor use of $\mathrm{CI}$ that held back the child's recovery. 
Overall, the results were better than expected; parents coping with their children's serious problems were happy with the decision to carry out cochlear implantation. They even recommended the procedure to other parents whose children had the same conditions, as reported in Wiley et al. ${ }^{7}$

\section{Conclusion}

An increase in communication and socio-emotional skills can give children with multiple deficiencies who use $\mathrm{CI}$ a better quality of life that extends to the whole family. Oral language development was found to be faster in children with bilateral implants, depending on the severity of their impairments. Small benefits created positive impacts, such as when a reaction to sound provoked great happiness. Despite the improvements observed in motor skills, agility, and muscle tone, emotional and/or relational problems, given their negative effect on potential progress, must be observed, and the affected individuals (whether parents or children) should be referred for psychological care. It is important to work toward diagnostic acceptance and adequate expectations, but the results are not always predictable, given the early age at which children receive $\mathrm{CI}-$ and parents should be aware of this. In conclusion, we propose the questionnaire that we developed in this study as adequate for these purposes.

\section{References}

1 Van Naarden K, Decouflé P, Caldwell K. Prevalence and characteristics of children with serious hearing impairment in metropolitan Atlanta, 1991-1993. Pediatrics 1999;103(03):570-575

2 Filipo R, Bosco E, Mancini P, Ballantyne D. Cochlear implants in special cases: deafness in the presence of disabilities and/or associated problems. Acta Otolaryngol Suppl 2004;(552):74-80

3 Fortnum HM, Marshall DH, Summerfield AQ. Epidemiology of the UK population of hearing-impaired children, including characteristics of those with and without cochlear implants-audiology, aetiology, comorbidity and affluence. Int J Audiol 2002;41(03):170-179

4 Hamzavi J, Baumgartner WD, Egelierler B, Franz P, Schenk B, Gstoettner W. Follow up of cochlear implanted handicapped children. Int J Pediatr Otorhinolaryngol 2000;56(03):169-174

5 Waltzman SB, Scalchunes V, Cohen NL. Performance of multiply handicapped children using cochlear implants. Am J Otol 2000;21 (03):329-335

6 Fukuda S, Fukushima K, Maeda Y, et al. Language development of a multiply handicapped child after cochlear implantation. Int J Pediatr Otorhinolaryngol 2003;67(06):627-633

7 Wiley S, Jahnke M, Meinzen-Derr J, Choo D. Perceived qualitative benefits of cochlear implants in children with multi-handicaps. Int J Pediatr Otorhinolaryngol 2005;69(06):791-798

8 Berrettini S, Forli F, Genovese E, et al. Cochlear implantation in deaf children with associated disabilities: challenges and outcomes. Int J Audiol 2008;47(04):199-208

9 Donaldson AI, Heavner KS, Zwolan TA. Measuring progress in children with autism spectrum disorder who have cochlear implants. Arch Otolaryngol Head Neck Surg 2004;130(05): 666-671

10 Institute GR. Regional and National Summary Report of Data from the 2009-10 Washington, DC: Gallaudet University; 2011 [cited 2015 July 23]. Available from: https://research.gallaudet.edu/ Demographics/2010_National_Summary.pdf

11 Boulet SL, Boyle CA, Schieve LA. Health care use and health and functional impact of developmental disabilities among US children, 1997-2005. Arch Pediatr Adolesc Med 2009;163(01):19-26

12 Lenarz T. Cochlear implants: selection criteria and shifting borders. Acta Otorhinolaryngol Belg 1998;52(03):183-199

13 Edwards LC. Children with cochlear implants and complex needs: a review of outcome research and psychological practice. J Deaf Stud Deaf Educ 2007;12(03):258-268

14 Meinzen-Derr J, Wiley S, Grether S, Choo DI. Functional performance among children with cochlear implants and additional disabilities. Cochlear Implants Int 2013;14(04):181-189

15 Jure R, Rapin I, Tuchman RF. Hearing-impaired autistic children. Dev Med Child Neurol 1991;33(12):1062-1072

16 Mulla I, Harrigan S, Gregory S, Archbold S. Children with complex needs and cochlear implants: The parent's perspective. Cochlear Implants Int 2013;14(S3):S38-S41

17 Barker R, Bathgate $F$. The challenges in providing rehabilitation for children with complex needs. Cochlear Implants Int 2013;14(S3): S29-S30

18 Robertson J. Children with cochlear implants and autism challenges and outcomes: The experience of the National Cochlear Implant Programme, Ireland. Cochlear Implants Int 2013;14(S3):S11-S4

19 Geers AE. Techniques for assessing auditory speech perception and lipreading enhancement in young deaf children. In Geers AE, Moog JS. Volta Rewiew 96: 85-96, 1994

20 Garrido M, Flores L. Categoría 7 de percepción del habla: Evalución de la comprensión del habla en ambientes naturales (2010). Integración 2014;72:23-29

21 Bevilacqua MC, Delgado EMC, Moret ALM. Estudo de casos clínicos e crianças do Centro Educacional do Deficiente Auditivo (CEDAU) do Hospital de Pesquisa e Reabilitação de Lesões Lábios-PalataisUSP. Encontro Internacional de Audiologia; 1996. Bauru (SP)

22 Azema B, Virole B. [Hearing aid for and clinical picture of deaf children with multiple handicaps]. Rev Laryngol Otol Rhinol (Bord) 1993;114(04):293-295

23 Steven RA, Green KM, Broomfield SJ, Henderson LA, Ramsden RT, Bruce IA. Cochlear implantation in children with cerebral palsy. Int J Pediatr Otorhinolaryngol 2011;75(11):1427-1430

24 Edwards LC, Frost R, Witham F. Developmental delay and outcomes in paediatric cochlear implantation: implications for candidacy. Int J Pediatr Otorhinolaryngol 2006;70(09):1593-1600

25 Meinzen-Derr J, Wiley S, Bishop S, Manning-Courtney P, Choo DI, Murray D. Autism spectrum disorders in 24 children who are deaf or hard of hearing. Int J Pediatr Otorhinolaryngol 2014;78(01): 112-118

26 Zaidman-Zait A, Young RA. Parental involvement in the habilitation process following children's cochlear implantation: an action theory perspective. J Deaf Stud Deaf Educ 2008;13(02): 193-214

27 Schoepflin J, Silverman CA, Linstrom CJ, Gilston NS, DeRose L. Parental restriction of children's access to cochlear implants: case studies. Cochlear Implants Int 2015;16(02):115-120 
Appendix 1

Name: Date of birth:

Today's date: Cl use period BILATERAL SEQUENTIAL

Mother's name: Date of cochlear implantation:

Associated disability(ies):

Daily amount of time used:
$>75 \%$ ( )
$50-75 \%($
$25-50 \%($
$<25 \%$ ( )

Was there any support from other family members prior to the decision for the cochlear implant (CI)? yes ( ) no ( )

Was there any support from the immediate family prior to the decision for the $\mathrm{Cl}$ ? yes（） no（） Was there any support from the Implant team prior to the decision for the $\mathrm{Cl}$ ?

yes( ) no ( )

Education:

Other therapies:

How hard has it been to take the child to all therapies? (Describe economic conditions, transportation issues, person responsible for taking the child, caregiver(s), work issues, instability of child behavior, etc.)

As a parent, what advantages of the cochlear implant have you seen? 
424 Benefit of Cochlear Implantation in Children Nasralla et al.

Communication Skills (refers to communication types as defined by the parents)

How did your child communicate before receiving the cochlear implant?

How does your child communicate now (with the cochlear implant)?

\section{Communication Skills (classifications based on subtitles):}

Has no intention of communicating (NIC)

Behavioral reactions (BR): crying, screaming, using facial expressions, vocalizing, and gesturing to communicate

Behavioral reactions/signals (BRS): same as above plus signals

Behavioral reactions/signals plus a few clear words (BRW)

Uses alternative communication (e.g., boards) (AC)

Signals (BSL): uses a formal system of signals, like Brazilian Sign Language (BSL)

Signals plus vocalization with communicative intent, even unintelligible words (SVC)

Oral/signal (OS): combination of BSL and clear spoken words

Oral $(\mathrm{O})$ : only words, no gestures or signals 
Socio-emotional Skills

Reacts to sound

Makes eye contact

Recognizes his/her own name

Likes music

Responds to verbal questions

Responds to people (explain how)

Communicates desires and needs

Siblings play with the child

Other children play with the

child

Does child look for the others

children?

Takes the initiative to play

\section{Cooperates with others}

Are others interested in the

child's progress?

\section{Adaptation:}

The child adapts to family routines.

It is comfortable to take the child to public places.

Does child exercise self-control?

Does child respond positively to new situations? 
426 Benefit of Cochlear Implantation in Children Nasralla et al.

Is child afraid to face the unknown?

Can child behave appropriately anywhere?

Openness to new

Pre-Cl

Post-Cl

experiences/learning styles:

Is curious

Demonstrates creativity

Explores new possibilities

Can solve problems

Is attentive and interested in

school

Is attentive and interested at

home

Is attentive and interested in

other therapies in general

Is interested in objects

\begin{tabular}{lll}
\hline Temperament: & Pre-Cl & Post-Cl \\
\hline Amiable & & \\
\hline
\end{tabular}

\section{Extrovert}

Joyful

Sad

Happier

Emotionally unstable 


\begin{tabular}{|c|c|c|}
\hline For his/her daily life activities: & Pre-Cl & Post-Cl \\
\hline Eating & $\begin{array}{c}\text { Dependent ( ) } \\
\text { Independent ( ) }\end{array}$ & $\begin{array}{c}\text { Dependent ( ) } \\
\text { Independent ( ) }\end{array}$ \\
\hline Dressing & $\begin{array}{c}\text { Dependent ( ) } \\
\text { Independent ( ) }\end{array}$ & $\begin{array}{c}\text { Dependent ( ) } \\
\text { Independent ( ) }\end{array}$ \\
\hline Going to the bathroom & $\begin{array}{c}\text { Dependent ( ) } \\
\text { Independent ( ) }\end{array}$ & $\begin{array}{c}\text { Dependent ( ) } \\
\text { Independent ( ) }\end{array}$ \\
\hline Taking a shower & $\begin{array}{l}\text { Dependent ( ) } \\
\text { Independent ( ) }\end{array}$ & $\begin{array}{c}\text { Dependent ( ) } \\
\text { Independent ( ) }\end{array}$ \\
\hline \multirow[t]{4}{*}{ Conscientiousness: } & Pre-Cl & Post-Cl \\
\hline & Organized ( ) & Organized ( ) \\
\hline & Persistent ( ) & Persistent ( ) \\
\hline & Resilient ( ) & Resilient ( ) \\
\hline
\end{tabular}

Generally, describe the level of success that you assign to the cochlear implant according to your expectations:

- As expected ( )

- Worse than expected ( )

- Better than expected ( )

- There was no expectation ( )

- I didn't know what to expect ( )

Would you recommend the cochlear implant to another child in the same condition?

$$
\text { YES ( ) NO( ) }
$$

COMMENTS:

\section{THANK YOU FOR YOUR PARTICIPATION!}

We hope, with the help of this questionnaire, to understand the contribution of the cochlear implant for children who have hearing loss and other changes in their development, thereby assisting your child and other children. 